\title{
Heat Shock Proteins Protect against Stress-related Phosphorylation of Tau in Neuronal PC12 Cells That Have Acquired Thermotolerance
}

\author{
Barbara A. Kirby, ${ }^{1,2}$ Carl R. Merril, ${ }^{2}$ Hossein Ghanbari, ${ }^{1}$ and William C. Wallace ${ }^{2}$ \\ 'Molecular Geriatrics Corporation, Lake Bluff, Illinois 60044 and 'Laboratory of Biochemical Genetics, NIMH, St. Elizabeths \\ Hospital, Washington, DC 20032
}

\begin{abstract}
A68, or PHF-tau, is an abnormally phosphorylated form of the microtubule-associated protein tau, which is a primary protein constltuent of paired helical filaments (PHFs) and, ultimately, of Alzheimer's disease-associated neurofibrillary tangles (NFTs). Previously, we have shown that in heatshocked neuronal PC12 cells, tau is hyperphosphorylated and transformed to an A68-like state as determined by immunologic and biochemical criteria. In the present study, we investigated the role of heat shock protein of $72 \mathrm{kDa}$ (hsp72) in the protection of tau against hyperphosphorylation during heat shock. Neuronal PC12 cells were exposed either directly to a heat shock $\left(45^{\circ} \mathrm{C}\right.$ for $\left.30 \mathrm{~min}\right)$ or to a conditioning heat stress $\left(43^{\circ} \mathrm{C}\right.$ for $90 \mathrm{~min}$ followed by a $4 \mathrm{hr}$ recovery at $37^{\circ} \mathrm{C}$ ) followed by the heat shock. Hsp72 was maximally induced immediately after heat shock in conditioned (acquired thermotolerant, ATT) cells, while unconditioned (nonacquired thermotolerant, non-ATT) cells required $9 \mathrm{hr}$ of recovery to exhibit maximal hsp72 induction. The differential time course of hsp72 induction during recovery of ATT and non-ATT cells correlated with the presence of normal tau. Immediately after the heat shock, when hsps were maximally induced, ATT cells exhibited the normal form of tau. With longer recovery times, the levels of $h$ sp72 were reduced and tau was hyperphosphorylated. A similar correlation was observed in non-ATT cells. In the presence of L-azetidyl 2-carboxylic acid, ATT cells synthesized nonfunctional hsp72, as exhibited by the inability of the cells to recover from the effects of heat shock. Under these conditions, tau was hyperphosphorylated despite the presence of elevated levels of hsp72. These results implicate functional hsp72 in the protection of tau from hyperphosphorylation and transformation to an A68-like state.
\end{abstract}

[Key words: A68-like tau, heat shock proteins, acquired thermotolerance, PC12 cells, phosphorylation, neurites]

The neurofibrillary tangle (NFT), a characteristic neuropathological structure present in Alzheimer disease (AD) brain tissues, is composed of paired helical filaments (PHFs). One constituent

\footnotetext{
Received Dec. 18, 1993; revised Feb. 28, 1994; accepted March 24, 1994.

We thank Dr. Gordon Guroff and G. Dickson at NIH for the generous gift of PC1 2 cells; Drs. L. Binder, R. Grossfeld, G. Johnson, W. Welch, and B. Wolozin for helpful discussions and critical reading of the manuscript; $D$. Brane and $N$. Hsu for excellent technical assistance; R. Sunberg and K. Christiansen for artwork; and Dr. S.-Y. Yang for use of the cell culture facility.

Correspondence should be addressed to William $\mathrm{C}$. Wallace, Laboratory of Biochemical Genetics, NIMH, St. Elizabeths Hospital, Washington, DC 20032

Copyright (C) 1994 Society for Neuroscience $0270-6474 / 94 / 145687-07 \$ 05.00 / 0$
}

of PHF reacts with the monoclonal antibody ALZ50. This constituent, termed A68 or PHF-tau, is a modified form of the microtubule-associated protein tau (Wood et al., 1986; Wischik et al., 1988; Ksiezak-Reding et al., 1988; Iqbal et al., 1989). A68 can be distinguished from normal tau by its electrophoretic mobility on SDS-PAGE and its antigenicity to ALZ50 (Wolozin et al., 1986; Ksiezak-Reding et al., 1990; Lee et al., 1991). A68 is an abnormally phosphorylated form of tau (Lee et al., 1991). The biochemical pathway by which the phosphoprotein tau is modified to form A68 and eventually incorporated into NFT during $\mathrm{AD}$ is not well characterized. Tau undergoes hyperphosphorylation in both fetal brain and tissues affected by neurodegenerative diseases (Bramblett et al., 1993; Goedert, 1993). Although some of the phosphorylation sites appear to be similar, the characterization of all A68 phosphorylation sites has not yet been completed (Ksiezak-Reding et al., 1992; Kenessey and Yen, 1993).

Differences in the extent and sites of phosphorylation of microtubule-associated proteins such as tau are believed to influence their binding to microtubules (Grundke-Iqbal et al., 1986; Biernat et al., 1993), and therefore microtubule stability (Kosik, 1992). In fetal brain development or regenerative responses (such as may occur in neurodegenerative diseases), hyperphosphorylation of tau may disrupt microtubule stability and facilitate subsequent neurite plasticity. In normal adult brain, in which synapses are maintained, tau is phosphorylated at fewer sites, which results in microtubule stability. Thus, hyperphosphorylation of tau in the $\mathrm{AD}$ brain may be associated with neurite breakdown.

Previously, we have shown that newly synthesized tau is phosphorylated to an A68-like state in neuronal PC12 cells (which are derived from rat pheocytochroma cells) exposed to heat shock (Wallace et al., 1993). This heat shock-induced form of tau was identified as A68-like by immunological, electrophoretic, and biochemical criteria (Wallace et al., 1993). This hyperphosphorylation may be due to activation of protein kinases during the heat shock (e.g., eIF- $2 \alpha$ kinase) or altered phosphorylatability of tau due to the stress. We also observed that precipitation of the heat-shocked PC12 lysates with antibody to hsp 72 revealed that tau, but not A68-like tau, coprecipitated with hsp 72 (Wallace et al., 1993). This result indicated that a stable association existed between normal tau and hsp 72 during heat shock. Based upon this finding and the proposed role of hsp72 as a cytoplasmic molecular chaperone (Beckman et al., 1990), we hypothesized that hsp 72 protected newly synthesized tau from the heat shock-induced hyperphosphorylation.

The AD brain exhibits elevated levels of hsp 72 synthesis and 


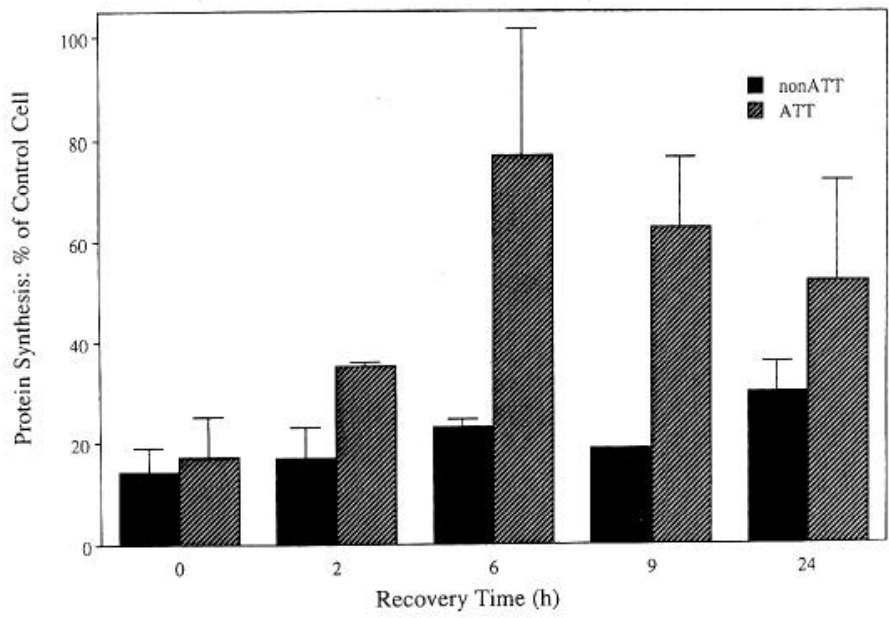

Figure 1. ATT cells recovered protein synthesis more rapidly after heat shock than non-ATT cells. Neuronal PC12 cells were either incubated at $43^{\circ} \mathrm{C}$ for $90 \mathrm{~min}$ and allowed to recover at $37^{\circ} \mathrm{C}$ for $4 \mathrm{hr}$ $(A T T)$ prior to heat shock or directly heat shocked (non-ATT). Heat shock consisted of a $30 \mathrm{~min}$ incubation at $45^{\circ} \mathrm{C}$. After heat shock, the cells were allowed to recover at $37^{\circ} \mathrm{C}$ for the indicated times after which they were labeled with ${ }^{35} \mathrm{~S}$-methionine/cysteine for $1 \mathrm{hr}$ as described in Materials and Methods. After lysis, total protein content and total ${ }^{35} \mathrm{~S}$ incorporation into protein were determined as described. The results present are the mean of four experiments $+1 \mathrm{SD}$.

accumulation (Perez et al., 1991) including incorporation into NFTs (Hamos et al., 1991). Exposure of a variety of cell types and organisms to a mild stress that induces hsps results in an increased resistance to a subsequent heat shock (Mizzen and Welch, 1988). This phenomenon is referred to as acquired thermotolerance (ATT) and is believed to result primarily from the elevated levels of hsps prior to the heat shock (Nover, 1991). Therefore, to test whether hsp 72 protects newly synthesized tau from the heat shock-induced hyperphosphorylation, neuronal PC12 cells were either conditioned and then exposed to heat shock (ATT cells) or exposed directly to heat shock (nonacquired thermotolerant, non-ATT, cells). The differential time courses of hsp 72 induction (early in ATT cells and delayed in non-ATT cells) were compared to the time courses of tau hyperphosphorylation. We observed that elevation of hsp72 synthesis either prior to heat shock (in ATT cells) or later during recovery (in non-ATT cells) was correlated with the expression of the normal form of tau, while control levels of hsp synthesis were correlated with the hyperphosphorylation of tau. Furthermore, we observed that neuronal cells containing the normal form of tau exhibited normal, stable neurites, while cells containing hyperphosphorylated tau exhibited disrupted, unstable neurites.

\section{Materials and Methods}

Cell Culture. PC12 cells were obtained from Dr. Gordon Guroff (National Institutes of Health) and maintained in DMEM containing 10\% horse serum, $5 \%$ fetal calf serum, $25 \mathrm{U} / \mathrm{ml}$ penicillin, and $100 \mu \mathrm{g} / \mathrm{ml}$ streptomycin under $5 \% \mathrm{CO}_{2}$. Cells were plated onto $100 \mathrm{~mm}$ petri dishes coated with rat tail collagen to an approximate density of $2 \times 10^{6}$ cells per dish. Cells were differentiated by treatment with nerve growth factor $(\beta$-NGF; $50 \mathrm{ng} / \mathrm{ml})$ for $7 \mathrm{~d}$ as described (Refolo et al., 1989). Neuronal differentiation was monitored by the presence of neurite processes.

Heat shock and radiolabeling. The standard experiment was performed as follows. After $7 \mathrm{~d}$ of treatment with NGF, neuronal PC12 cells were conditioned by placement in a water bath set at $43^{\circ} \mathrm{C}$ for 90
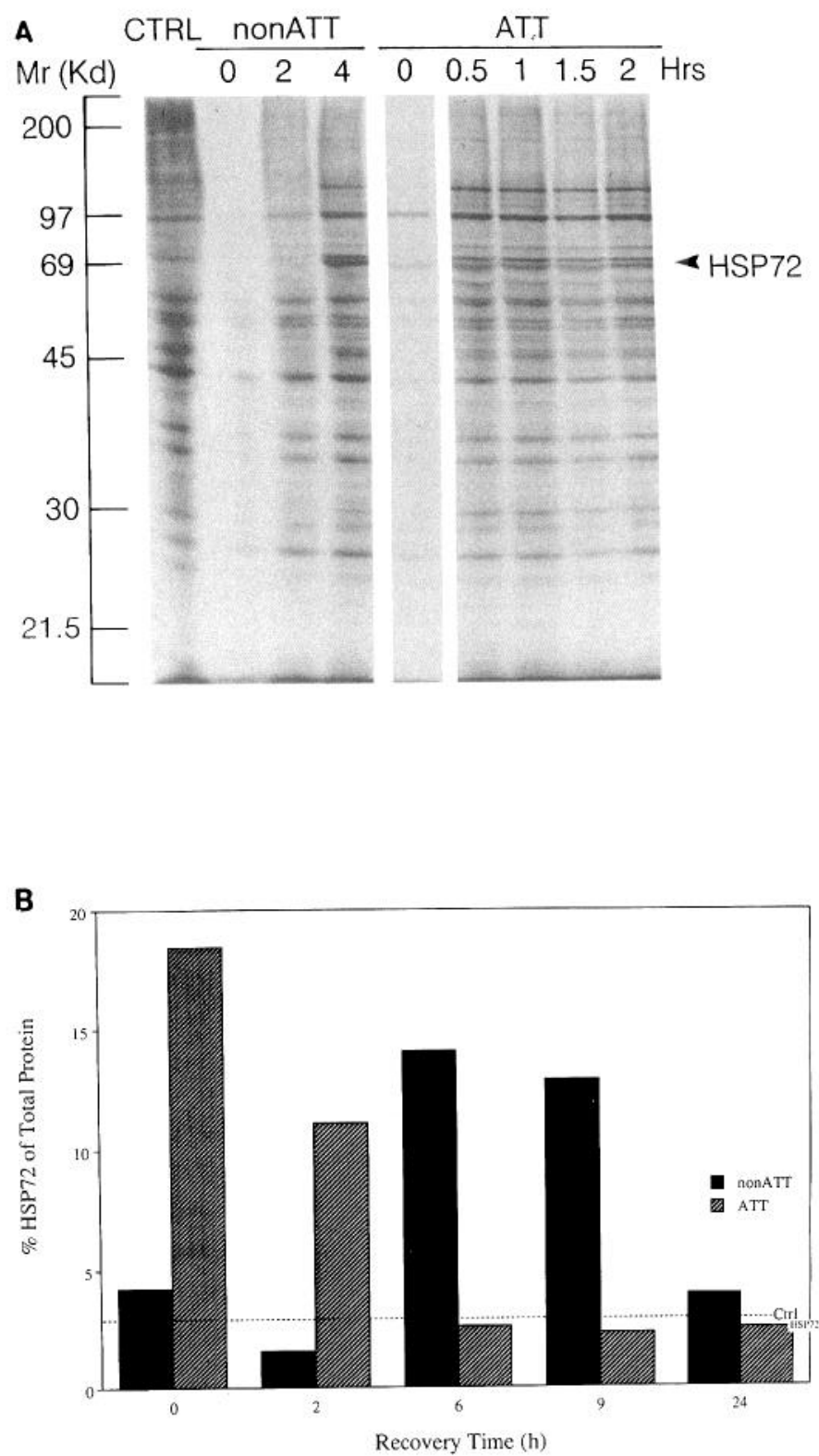

Figure 2. ATT cells induced hsps earlier and to a greater extent than non-ATT cells during recovery. $A$, Cells were treated to acquire thermotolerance $(A T T)$ or control (nonATT), heat shocked, and labeled, and total protein content was determined as described in Materials and Methods. Equal aliquots of total cellular protein $(16 \mu \mathrm{g})$ were separated by SDS-PAGE on $10 \%$ polyacrylamide gels and the ${ }^{35} \mathrm{~S}$-labeled proteins visualized by autoradiography. Shown are various recovery times after heat shock for ATT and non-ATT cells from a representative experiment. Control cells $(C T R L)$ were non-ATT cells that were not heat shocked. The arrow denotes hsp72 as determined by electrophoretic mobility and abundance (see also Fig. 9). The absence of ${ }^{35}$ S-polypeptides at $0 \mathrm{hr}$ after heat shock is consistent with the reduced protein synthesis in these cells (see Fig. 1). B, The relative amount of hsp72 synthesis was quantitated by densitometry and expressed as the percentage of total ${ }^{35} \mathrm{~S}$-protein detected on the gel. The horizontal dotted line denotes the percentage hsp 72 synthesis observed in control nonheat-shocked cells. The results presented are from a single representative experiment. Similar results showing ATT cells more rapidly induced hsp72 than non-ATT cells but with slightly different time courses were obtained from six other experiments. 


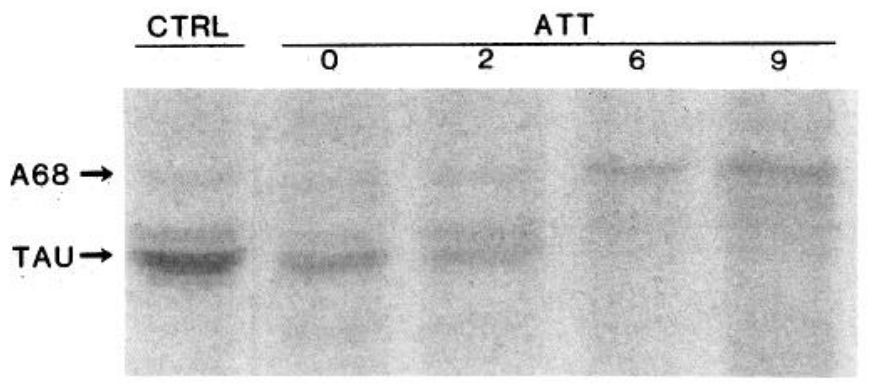

Figure 3. ATT cells retained tau in its normal form initially after heat shock but with recovery, tau is hyperphosphorylated. Cells were treated for acquired thermotolerance $(A T T)$, heat shocked, and labeled as described in Materials and Methods. ${ }^{35} \mathrm{~S}$ lysates were immunoprecipitated with TAU2 antibody and visualized by SDS-PAGE and autoradiography as described in Materials and Methods. Shown are the immunoprecipitates for ATT cells at various times of recovery from heat shock. The lower arrow denotes normal tau and the upper arrow denotes the hyperphosphorylated (A68-like) form of tau, as determined by their immunological, electrophoretic, and ${ }^{32} \mathrm{P}$ radiolabeling properties described previously (Wallace et al., 1993).

min and then returned to the $37^{\circ} \mathrm{C}$ incubator for $4 \mathrm{hr}$ prior to heat shock. These cells are referred to as acquired thermotolerant, or ATT, cells. Both conditioned ATT cells and unconditioned non-ATT cells were heat shocked by incubation in a $45^{\circ} \mathrm{C}$ water bath for $30 \mathrm{~min}$. After heat shock, fresh media were added to all cells, which were then returned to the $37^{\circ} \mathrm{C}$ incubator for recovery for various periods of time as presented in the results. Following recovery, the cells were photographed using a Nikon TMS microscope and Nikon FX-35A camera and radiolabeled with ${ }^{35} \mathrm{~S}$-methionine/cysteine $(100 \mu \mathrm{Ci} / \mathrm{ml}$ in DMEM lacking nonradiolabeled methionine) for $60 \mathrm{~min}$. Conditioned media from the cells were centrifuged with a clinical centrifuge at $4^{\circ} \mathrm{C}$ for $10 \mathrm{~min}$ at 2000 $\mathrm{rpm}$ to harvest detached cells. Preliminary experiments indicated that the detached cells exhibited the same relevant cellular and biochemical characteristics as the attached cells. Therefore, both attached and detached labeled cells were lysed at $4^{\circ} \mathrm{C}$ using $1 \%$ NP-40, $50 \mathrm{~mm}$ Tris, $\mathrm{pH}$ 7.4, $5 \mathrm{~mm}$ EDTA, $10 \mu \mathrm{g} / \mathrm{ml}$ leupeptin, $10 \mu \mathrm{g} / \mathrm{ml}$ pepstatin, and $0.5 \mathrm{~mm}$ PMSF. The combined attached/detached cell lysates were centrifuged for $10 \mathrm{~min}$ at $1500 \mathrm{rpm}$ at $4^{\circ} \mathrm{C}$ in an Eppendorf microfuge. The supernate was used for all experiments.

Examination of ${ }^{35}$ S-labeled proteins. Total protein content was determined by Bradford assay. Total incorporation of ${ }^{35} \mathrm{~S}$-label into protein was determined by precipitation of cellular lysates with trichloroacetic acid onto $3 \mathrm{M}$ paper. Total ${ }^{35} \mathrm{~S}$-labeled protein was visualized by either SDS-polyacrylamide gel electrophoresis using $10 \%$ polyacrylamide gels or two-dimensional gel electrophoresis using $\mathrm{pH}$ 3-10 ampholines and $10 \%$ polyacrylamide gels. The various forms of tau were immunoprecipitated from cellular lysates using either TAU2 antibody and fixed staphylococcus aureus as the secondary antibody or ALZ50 and antimouse IgM bound to Sepharose beads as secondary antibody. TAU2 immunoprecipitates tau in its various phosphorylated forms and ALZ50 immunoprecipitates only the hyperphosphorylated form of tau (Wallace et al., 1993) TAU2 was obtained from Sigma while ALZ50 was a generous gift from Dr. Peter Davies, Albert Einstein School of Medicine.

After electrophoresis, gels were dried for autoradiography. All radiolabeled gels were exposed to film for various times in order to obtain multiple exposures to ensure linearity of signal. ${ }^{35} \mathrm{~S}$-proteins were quantitated by densitometry using a densitometer and IMAGE 4.1 software program (W. Raspin, National Institutes of Health).

\section{Results}

ATT cells recovered protein synthesis more rapidly after heat shock than non-ATT cells

A primary effect of heat shock is the inhibition of protein synthesis (Welch et al., 1989). We examined whether acquired thermotolerance (ATT) enhanced recovery of protein synthesis following heat shock $\left(45^{\circ} \mathrm{C}\right.$ for $\left.30 \mathrm{~min}\right)$. Protein synthesis was

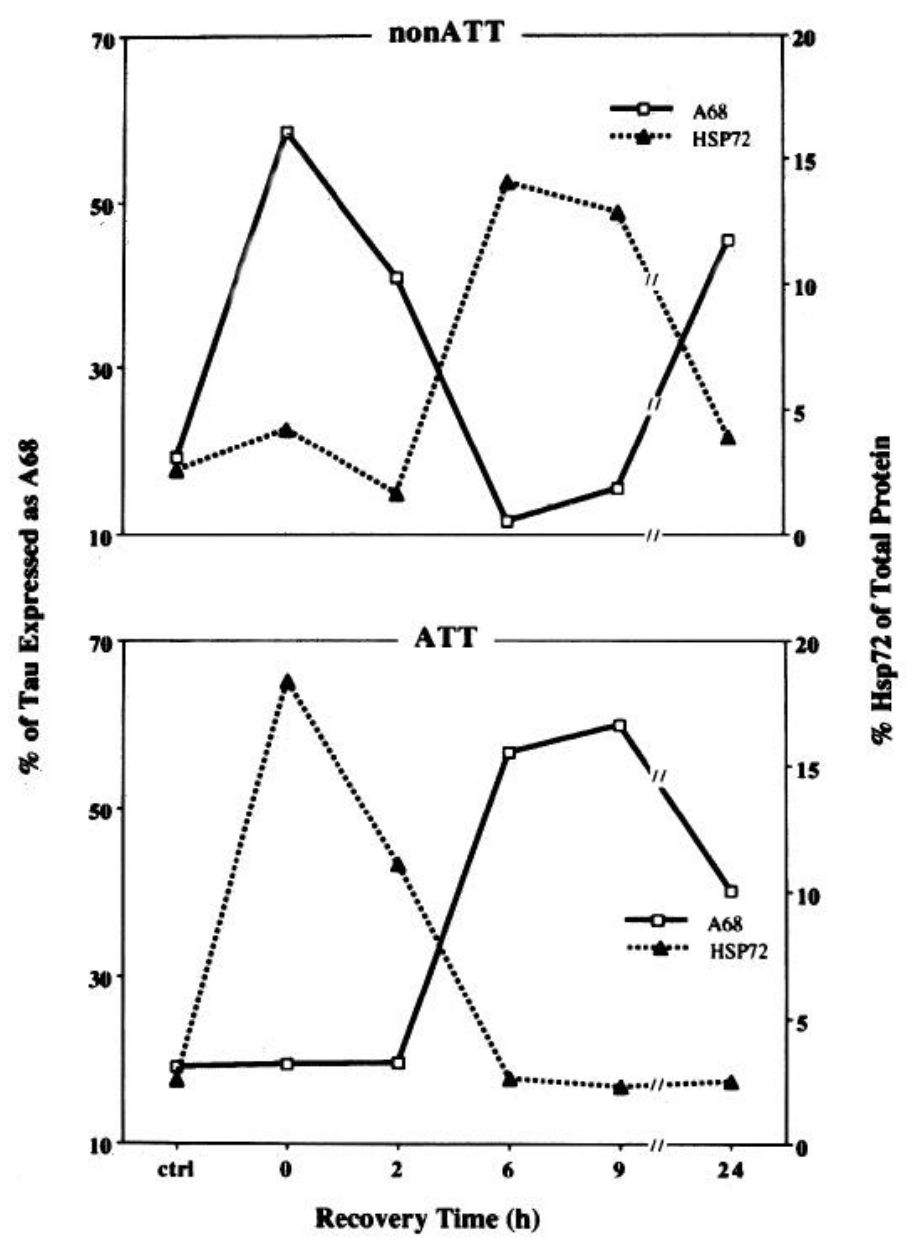

Figure 4. The hyperphosphorylation of tau correlated with control levels of hsp 72 synthesis in both non-ATT and ATT cells. Cells were treated to acquire thermotolerance (ATT) or control (nonATT), heat shocked, and labeled as described in Materials and Methods. The cells were allowed to recover from the heat shock for various times as indicated. ${ }^{35} \mathrm{~S}$-hsp 72 content was determined (as described in Fig. 2) and is expressed as the percentage of total protein synthesis (see Fig. 2). ${ }^{35} \mathrm{~S}$ tau was immunoprecipitated and visualized as described in Figure 3. The normal and hyperphosphorylated forms of tau (as defined in Fig. 3) were quantitated by densitometry (as described in Materials and Methods). The levels of A68-like tau are expressed as the percentage of ${ }^{35} \mathrm{~S}$ present in the upper band of the immunoprecipitates compared to that in the upper and lower bands together. For clarity, the results presented are from a representative experiment of three replications.

assayed at various times of recovery after heat shock by determining incorporation of ${ }^{35} \mathrm{~S}$-methionine into TCA-precipitible material. In ATT cells, maximum recovered protein synthesis was $77 \%$ of control (non-heat shocked) cell synthesis by $6 \mathrm{hr}$ of recovery from heat shock (Fig. 1). In contrast, in non-ATT cells, maximum recovered protein synthesis was only $30 \%$ of control cell synthesis, which was attained $24 \mathrm{hr}$ after heat shock.

\section{ATT cells induced hsps earlier and to a greater extent than non-ATT cells during recovery}

Induction of hsp72 synthesis was readily apparent with examination of newly synthesized proteins by SDS-PAGE and autoradiography (Fig. 2A). In ATT cells, expression of hsp72 was maximally elevated immediately after heat shock $(18 \%$ of total protein synthesis) (Fig. 2B). Expression returned to control rates 
A

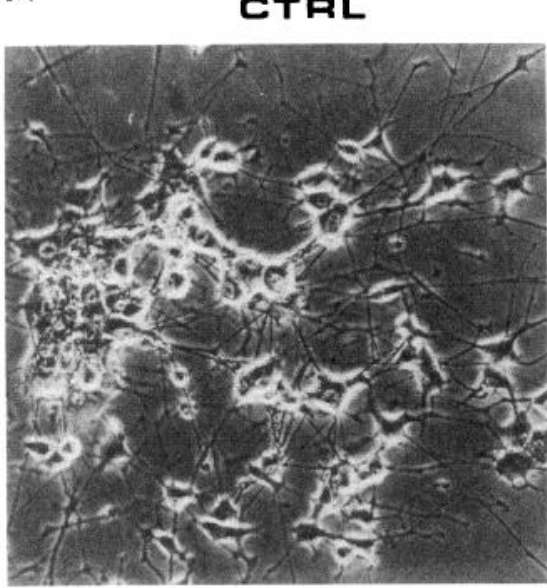

NONATT

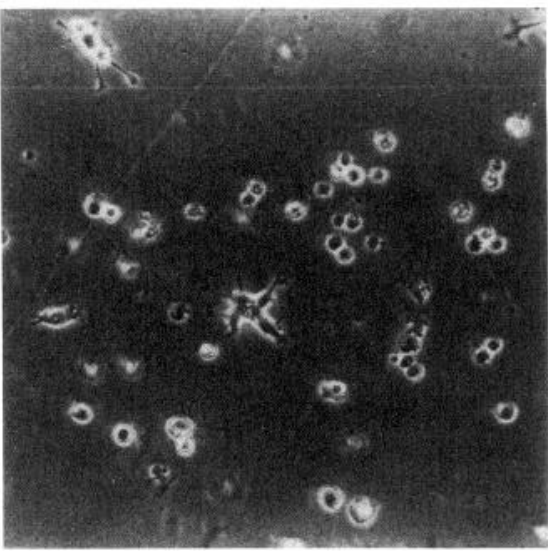

ATT

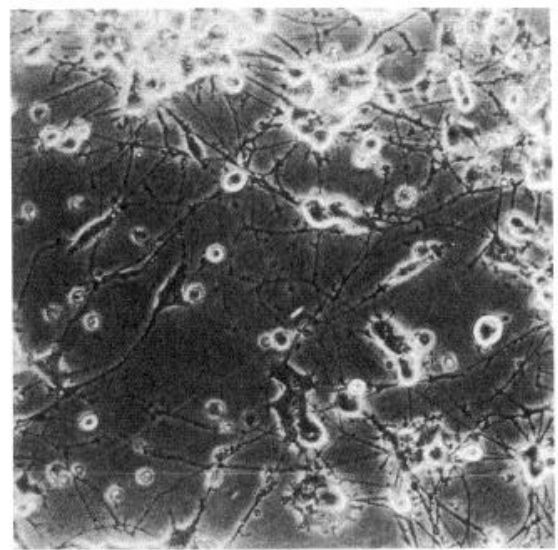

B

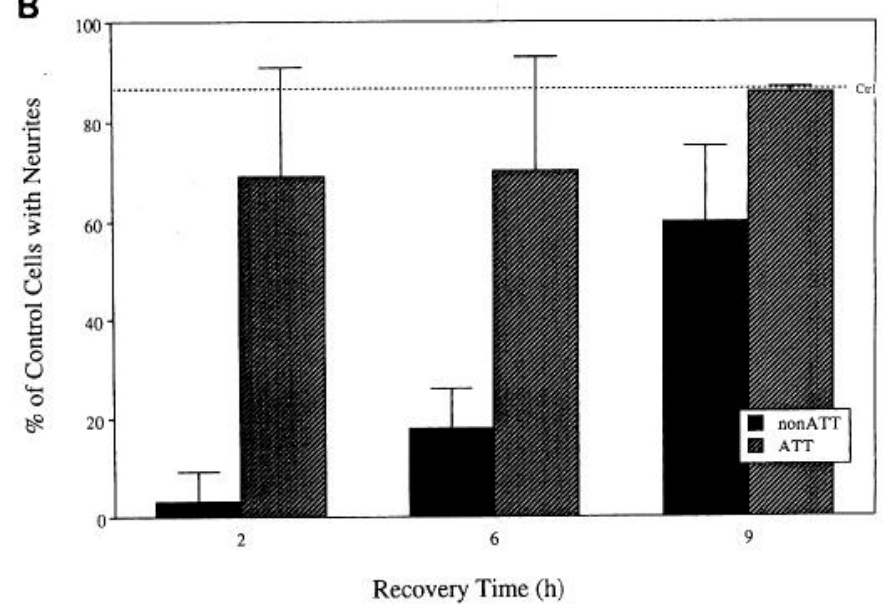

Figure 5. ATT cells regenerated neurites rapidly after heat shock. $A$, Neuronal PC1 2 cells were treated to acquire thermotolerance $(A T T)$ or control $($ NONATT $)$ as described in Materials and Methods. After heat shock, the cells were allowed to recover at $37^{\circ} \mathrm{C}$ for $2 \mathrm{hr}$. Shown are representative examples of photomicrographs of each culture. CTRL refers to non-ATT cells that were not heat shocked. $B$, The number of cells that exhibited neurites was determined by scoring photomicrographs (100 cells per field and four random fields for each culture) of ATT and non-ATT cells at various times during recovery from heat shock. The horizontal dotted line denotes the percentage of cells exhibiting neurites in non-ATT cells without heat shock $(C T R L)$. The results are the mean of five experiments $+1 \mathrm{SD}$.

of synthesis ( $3 \%$ of total protein synthesis) after $6 \mathrm{hr}$ of recovery from heat shock. In non-ATT cells, expression of hsp72 was not elevated until $6 \mathrm{hr}$ after heat shock and attained a maximum at $9 \mathrm{hr}$ ( $15 \%$ of total protein synthesis). Expression of hsp72 returned to control rates of synthesis at later time points.

The hyperphosphorylation of newly synthesized tau correlated with control levels of hsp 72 synthesis in both non-ATT and ATT cells

Immunoprecipitation of ATT cell ${ }^{35} \mathrm{~S}$-proteins with TAU2 antibody indicated a delayed hyperphosphorylation of newly synthesized tau with recovery (Fig. 3). The time courses of the tau hyperphosphorylation were different in cells with and without ATT (Fig. 4). In ATT cells, tau was expressed in its normal form in the immediate times after heat shock when hsp 72 synthesis was elevated. Later, when synthesis of hsp 72 returned to control levels, tau was hyperphosphorylated. In non-ATT cells, tau was hyperphosphorylated in the immediate times after heat shock when hsp synthesis was not yet elevated. From 6 to $9 \mathrm{hr}$ after heat shock, when hsp 72 synthesis was elevated, tau existed predominantly in its normal form. Later, when hsp 72 synthesis was reduced, some tau was hyperphosphorylated. Thus, at all times, cells with or without ATT contained predominantly the normal form of tau when hsp72 levels were elevated.

\section{ATT cells regenerated neurites rapidly after heat shock}

Upon heat shock, neuronal PC12 cells underwent morphological changes, including loss of neurites and rounding up (Fig. $5 \mathrm{~A}$ ). Eventually, most cells recovered from these alterations to exhibit the typical morphology of a neuronal PC12 cell, as represented by the number of cells that possess neurites (Fig. $5 B$ ). The majority of ATT cells (70\%) exhibited neurites $2 \mathrm{hr}$ after the heat shock, although the neurites appeared somewhat shorter than those of control cells (Fig. $5 A$ ). Non-ATT cells required 9 $\mathrm{hr}$ until a majority of them exhibited neurites.

\section{Acquired thermotolerance was inhibited by L-azetidyl 2-carboxylic acid, a drug that disrupts hsp function}

It has been shown that cells treated with L-azetidyl 2-carboxylic acid (AZC), an analog of proline, synthesized nonfunctional hsps 
CTRL

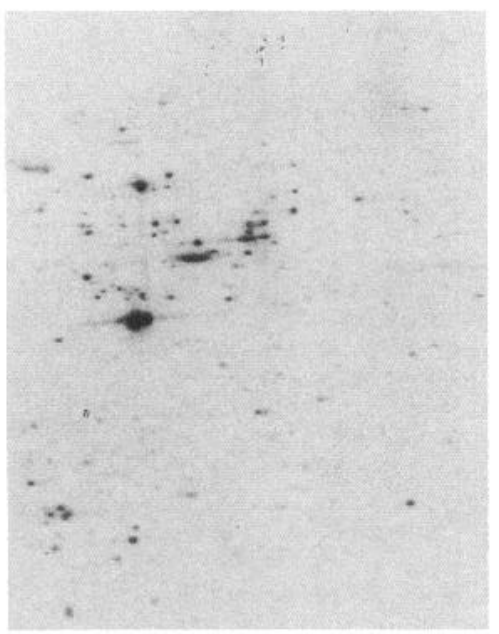

ATT

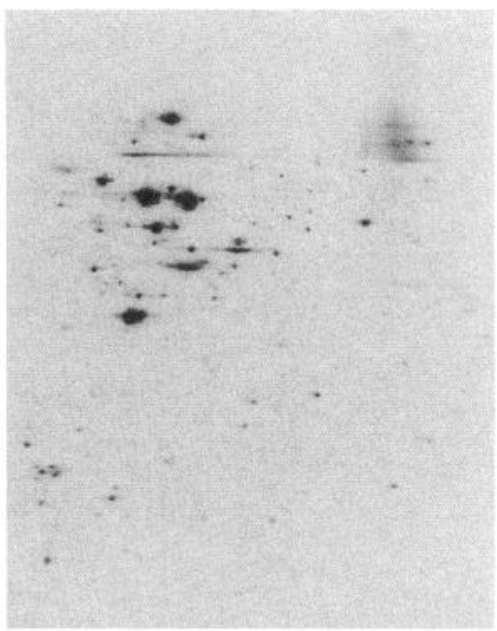

$\mathrm{ATT}+\mathrm{AZC}$

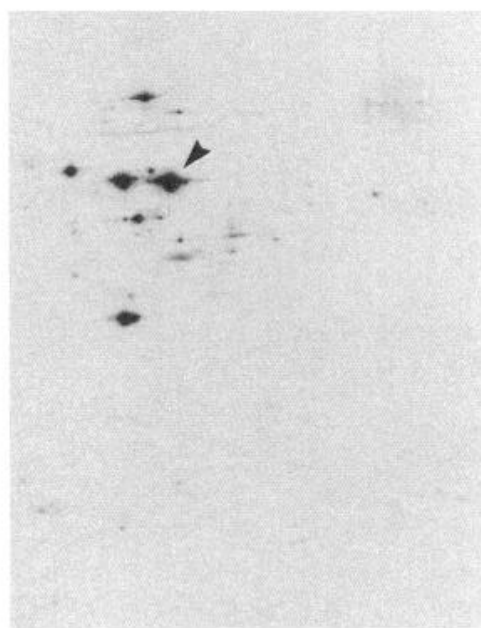

Figure 6. AZC-treated ATT cells expressed elevated levels of hsp 72 with heat shock. Neuronal PC12 cells were treated to acquire thermotolerance $(A T T)$ as described in Materials and Methods. Control cells $(C T R L)$ were non-ATT and not heat shocked. AZC-treated cells $(A T T+A Z C)$ were incubated in the presence of $5 \mathrm{~mm} \mathrm{AZC}$ in culture media for $6 \mathrm{hr}$. All samples were immediately labeled with ${ }^{35} \mathrm{~S}$ after heat shock (no recovery time) and the ${ }^{35}$ S-protein obtained and separated on two dimensional gels as described in Materials and Methods. Each gel represents $40 \mu \mathrm{g}$ of total protein. The lower amount of ${ }^{35} \mathrm{~S}$-protein on the gel of the heat shock sample indicates the reduced protein synthesis in non-ATT cells. Hsp72 is denoted by the arrowhead.

and thus do not recover from the effects of heat shock (Welch and Mizzen, 1988). Therefore, AZC was used to confirm that hsp function was essential for neuronal PC12 cell recovery after heat shock. Upon heat shock, AZC-treated ATT cells synthesized hsp at elevated levels comparable to untreated ATT cells (Fig. 6). However, despite the induction of hsp72, recovery of protein synthesis was inhibited in the AZC-treated ATT cells (Fig. 7). Likewise, these same cells did not regenerate neurites by $9 \mathrm{hr}$ after heat shock (Fig. 7). AZC treatment in the absence of heat shock did not cause loss of neurites (data not shown). These two observations indicated that the induced hsps present in the AZC-treated cells were nonfunctional. The form of newly synthesized tau present in these cells was determined by immunoprecipitation of newly synthesized protein with TAU2. Both control (non-heat shocked, lane 1) and ATT cells (lane 2) exhibited predominantly the normal form of tau (Fig. 8). However, AZC-treated ATT cells (lane 3) showed that 29\% of tau (compared to $0 \%$ of ATT cells, lane 2) was expressed as A68like tau in the presence of the drug.

\section{Discussion}

Previously, we have shown that neuronal PC12 cells that were subjected to a heat shock exhibited a hyperphosphorylated form of newly synthesized tau (Wallace et al., 1993). A similar modification has been reported in heat-shocked rat brain (Paposozomenos and $\mathrm{Su}, 1991)$. On the other hand, heat-shocked human neuroblastoma cells exhibit dephosphorylated forms of mature tau (Chiang et al., 1993). Recovery of the heat-shocked neuronal PC12 cells resulted in the reversion to normally phosphorylated tau. We also found that a fraction of tau polypeptides in the heat-shocked cells complexed with the hsp72 and remained in the normal form (Wallace et al., 1993). We proposed that these normal tau proteins were associated with hsp72, a molecular chaperone, and thereby protected from the heat shockrelated phosphorylation that transform tau to the A68-like state.

In this investigation, we have implicated hsp 72 in the pro- tection of newly synthesized tau from hyperphosphorylation in neuronal PC12 cells. As reported earlier (Mizzen and Welch, 1988), non-neuronal cells that were exposed to a conditioning heat stress and allowed to recover (ATT cells) survived the effects of a subsequent normally lethal heat shock. The protection accorded these ATT cells was due, at least in part, to the induction of hsp 72 during the conditioning heat stress. We found that neuronal PC12 cells with ATT recovered more rapidly from heat shock, as evidenced by recovery of protein synthesis (Fig. 1) and regeneration of neurites (Fig. 5B). ATT cells exhibited a time course of elevated hsp 72 synthesis after heat shock different from that of non-ATT cells (Fig. 2). We took advantage of the

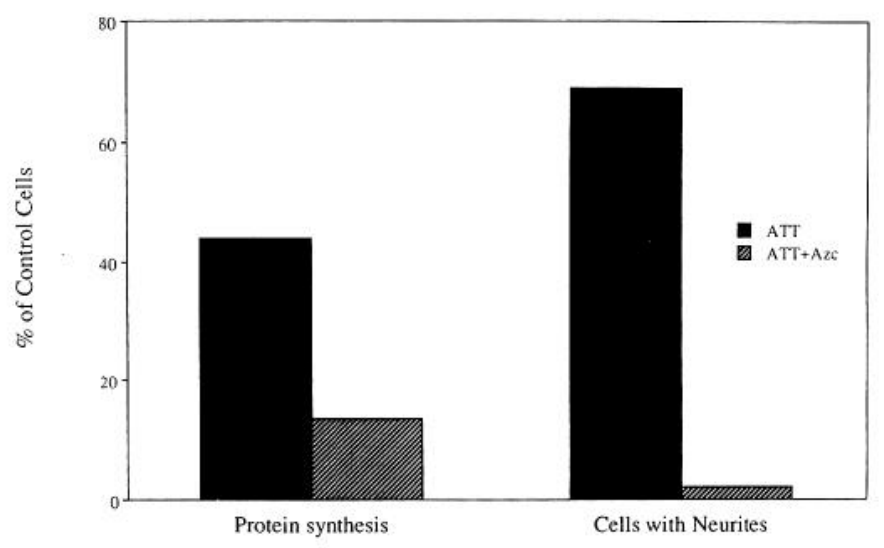

Figure 7. AZC-treated ATT cells exhibit reduced protein synthesis and loss of neurites. Neuronal PC12 cells were treated to acquire thermotolerance $(A T T)$ as described in Materials and Methods and some samples treated with AZC as described in Figure 6. After heat shock, cells were allowed to recover for $2 \mathrm{hr}$ and were then labeled with ${ }^{35} \mathrm{~S}$ (to assay protein synthesis) or photomicrographed (to assay neurite number). Presented are the results of a single representative experiment (for protein synthesis) and the average of two experiments (for neurite number). 


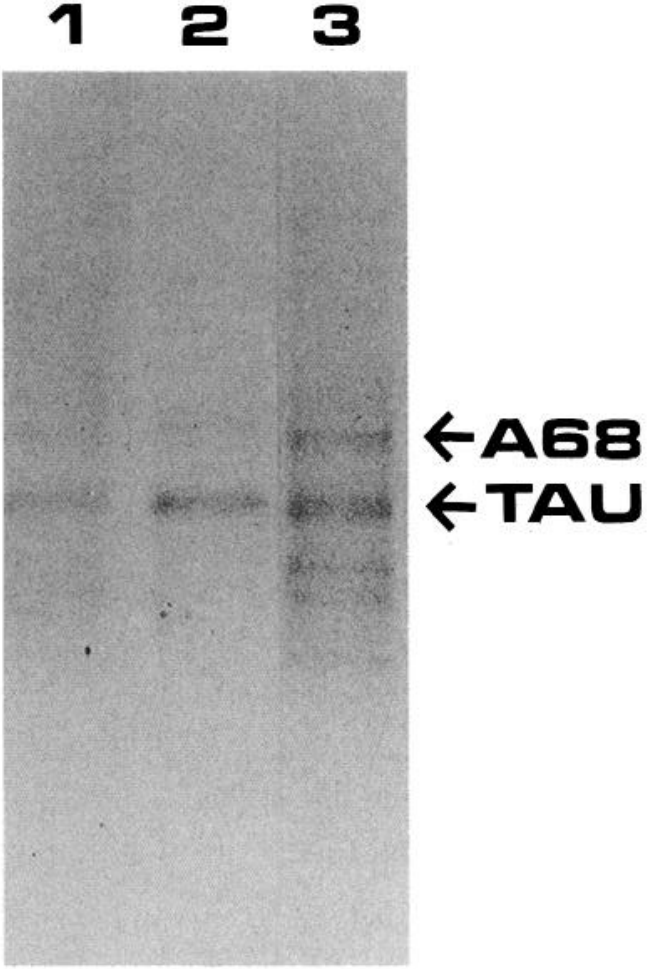

Figure 8. The form of tau in AZC-treated ATT cells. Cells were treated to acquire thermotolerance and with $\mathrm{AZC}$ as described in Figure 7. After heat shock, total ${ }^{35}$ S-protein was immunoprecipitated with TAU2 antibody and separated by SDS-PAGE. The resulting gels were exposed to film for autoradiography. Shown are the immunoprecipitates from control (non-ATT, nonheat-shocked, lane 1), ATT (lane 2), and AZCtreated ATT (lane 3) cells.

differential time courses to examine the form of newly synthesized tau present with elevated (ATT cells) or control levels (non-ATT cells) of hsp72 synthesis prior to heat shock. For both types of cells, the presence of the control levels of hsp72 synthesis (for non-ATT cells, 0-2 hr during recovery; for ATT cells, 6-24 hr during recovery), correlated with the presence of hyperphosphorylated tau. Conversely, elevated levels of hsp72 synthesis (for non-ATT cells, 6-9 hr during recovery; for ATT cells, $0-2 \mathrm{hr}$ during recovery) correlated with the presence of normal tau. This correlation implied that cells containing elevated levels of hsp72 were protected from the hyperphosphorylation of tau. To further implicate a role for hsp72 in retaining tau in its normal form, we used the proline analog AZC. AZC induces synthesis of nonfunctional hsp (Welch and Mizzen, 1988; Beckman et al., 1989) that inhibits the normal recovery of cells from heat shock (Welch and Mizzen, 1988). In the presence of 5 mм AZC, ATT cells exhibited less recovery from heat shock, including reduced protein synthesis and loss of neurites, indicating that the protective effects of ATT were negated by the AZC (Fig. 7). The loss of hsp function with AZC treatment also resulted in the hyperphosphorylation of tau in ATT cells that were normally protected from this modification (Fig. 8).

We also observed a correlation between the form of newly synthesized tau and the presence of neurites on the cells. Under those conditions in which tau was hyperphosphorylated, the neuronal PC12 cells exhibited few or no neurites. A notable exception to this correlation was the longest recovery time for the heat-shocked non-ATT cells (Fig. 4). This observed rela- tionship, taken together with reports that A68 binds poorly to microtubules in vitro (Grundke-Iqbal et al., 1986; Bramblett et al., 1993), provides additional evidence that the highly phosphorylated forms of tau alter the structural integrity of the cytoskeleton, and thus the maintenance and growth of neurites (Kosik, 1992).

In summary, we have implicated that hsp72, a stress-induced protein that acts as a molecular chaperone (Beckman et al., 1990), protects against the specific hyperphosphorylation of tau, an event associated with neurodegeneration. Normally, heat shock of neuronal $\mathrm{PC} 12$ cells results in the hyperphosphorylation of newly synthesized tau to an A68-like state. Four observations implicate a role for $\mathrm{hsp} 72$ in protecting against the heat shock-related phosphorylation of tau. First, coprecipitation experiments showed that only normal tau complexed with hsp72 during heat shock (Wallace et al., 1993). Second, ATT cells, which contained elevated levels of hsp72 prior to and immediately after heat shock, exhibited normal tau immediately after the heat shock. Third, at various times of recovery in cells with and without ATT, the appearance of normal tau was correlated with elevated synthesis of hsp72. Fourth, in the presence of AZC, a drug that induces nonfunctional hsps (Welch and Mizzen, 1988), tau was hyperphosphorylated, even in ATT cells. These results indicate that the neuronal heat shock response can inhibit the phosphorylation of newly synthesized tau to an A68like state and prevent the destabilization and subsequent loss of neurites that occurs as a result of this tau modification.

\section{References}

Beckman RP, Mizzen LA, Welch WJ (1990) Interaction of hsp70 with newly synthesized proteins: implications for protein folding and assembly. Science 248:850-854.

Biernat J, Gustke N, Drewes G, Mandelkow E-M, Mandelkow E (1993) Phosphorylation of ser 262 strongly reduces binding of tau to microtubules: distinction between PHF-like immunoreactivity and microtubule binding. Neuron 11:153-163.

Bramblett GT, Goedert M, Jakes R, Merrick SE, Trojanowski JQ, Lee VM-Y (1993) Abnormal tau phosphorylation at Ser396 in Alzheimer's disease recapitulates development and contributes to reduced microtubule binding. Neuron 10:1089-1099.

Chiang MF, Wan-Kyng L, Yen S-H (1993) Reversible heat stressrelated loss of phosphorylated Alzheimer-type epitopes in tau proteins of human neuroblastoma cells. J Neurosci 13:4854-4860.

Goedert M (1993) Tau protein and the neurofibrillary pathology of Alzheimer's disease. Trends Neurosci 16:460-465.

Grundke-Iqbal I, Iqbal K, Tung Y-C, Quinlan M, Wisniewski HM, Binder LI (1986) Abnormal phosphorylation of the microtubuleassociated protein $\tau$ (tau) in Alzheimer cytoskeletal pathology. Proc Natl Acad Sci USA 83:4913-4917.

Hamos JE, Oblas B, Pulaski-Salo D, Welch WJ, Bole DG, Drachman DA (1991) Expression of heat shock proteins in Alzheimer's disease. Neurology 41:345-350.

Hyman BT, Van Hoesen GW, Wolozin BL, Davies P, Kromer LJ, Damasio AR (1988) Alz-50 antibody recognizes Alzheimer-related neuronal changes. Ann Neurol 23:371-379.

Iqbal K, Grunde-Iqbal I, Smith AJ, George L, Tung Y-C (1989) Identification and localization of a peptide to paired helical filaments of Alzheimer disease. Proc Natl Acad Sci USA 86:5646-5650.

Kenessey A, Yen S-HC (1993) The extent of phosphorylation of fetal tau is comparable to that of PHF-tau from Alzheimer paired helical filaments. Brain Res 629:40-46.

Kosik KS (1992) Alzheimer's disease: a cell biological perspective. Science 256:780-783.

Ksiezak-Reding H, Davies P, Yen S-H (1988) Alz-50, a monoclonal antibody to Alzheimer's disease antigen, cross-reacts with $\tau$ proteins from bovine and normal human brain. J Biol Chem 263:7943-7947.

Ksiezak-Reding H, Binder LI, Yen S-H (1990) Alzheimer disease proteins (A68) share epitopes with tau but show distinct biochemical properties. J Neurosci Res 25:420-430. 
Ksiezak-Reding H, Liu W-K, Yen SH (1992) Phosphate analysis and dephosphorylation of modified tau associated with paired helical filaments. Brain Res 597:209-219.

Lee VM-Y, Balin BJ, Otvos L, Trojanowski JQ (1991) A68: a major subunit of paired helical filaments and derivatized forms of normal tau. Science 251:675-678.

Mizzen LA, Welch WJ (1988) Characterization of the thermotolerant cell. I. Effects on protein synthesis activity and the regulation of heatshock protein 70 expression. J Cell Biol 106:1105-1116.

Nover L (1991) Induced thermotolerance. In: Ileat shock response (Nover L, ed), pp 409-452. Boca Raton, FL: CRC.

Paposozomenos SCH, Su Y (1991) Altered phosphorylation of tau protein in heat-shocked rats and patients with Alzheimer's disease. Proc Natl Acad Sci USA 88:4543-4547.

Perez N, Sugar J, Charya S, Johnson G, Merrill C, Bierer L, Perl D, Haroutunian V, Wallace W (1991) Increased synthesis and accumulation of heat shock 70 proteins in Alzheimer's disease. Mol Brain Res 11:249-254.

Refolo LM, Salton SRJ, Anderson JP, Mehta P, Robakis NK (1989) Nerve and epidermal growth factors induce the release of the Alzheimer amyloid precursor protein from PC12 cell cultures. Biochem Biophys Res Commun 164:664-670.
Wallace W, Johnson G, Sugar J, Merril CR, Refolo LM (1993) Reversible phosphorylation of tau to form A68 in heat-shocked neuronal PC1 2 cells. Mol Brain Res 19:149-155.

Welch WJ, Mizzen LA (1988) Characterization of the thermotolerant cell. II. Effects on the intracellular distribution of heat-shock protein 70 , intermediate filaments, and small nuclear ribonucleoprotein complexes. J Cell Biol 106:1117-1130.

Welch WJ, Mizzen LA, Arrigo A-P (1989) Structure and function of mammalian stress proteins. In: Stress induced proteins (Pardue ML, Feramisco JR, Lindquist S, eds), pp 187-202. New York: Liss.

Wischik CM, Novak M, Thogersen HC, Edwards PC, Runswick MJ, Jakes R, Walker JE, Milstein C, Roth M, Klug A (1988) Isolation of a fragment of tau derived from the core of the paired helical filament of Alzheimer disease. Proc Natl Acad Sci USA 85:4506-4510.

Wolozin BL, Pruchnicki A, Dickson DW, Davies P (1986) A neuronal antigen in the brains of Alzheimer patients. Science 232:648-650.

Wood J, Mirra S, Pollock N, Binder L (1986) Neurofibrillary tangles of Alzheimer's disease share antigenic determinants with the axonal microtubule-associated protein tau. Proc Natl Acad Sci USA 83:40404043. 